\title{
Psychological Impact of COVID-19 Cases on Medical Staff of Beijing Xiaotangshan Hospital
}

This article was published in the following Dove Press journal:

Psychology Research and Behavior Management

\begin{abstract}
Yuanbo Fu, ',* Mina Wang, I,2,* Bingcong Zhao,',* Baoli Liu, ${ }^{3}$ Jie Sun, ${ }^{4}$ Yaohui Feng, ${ }^{3}$ Zhengrang Wang, ${ }^{3}$ Qian Li, ${ }^{3}$ Chunhong Shi, ${ }^{3}$ Yabo Xuan, ${ }^{3}$ Siqi Long, ${ }^{3}$ Huan Liu, ${ }^{4}$ Tiange Chi, ${ }^{5}$ Zehuan Liao, (D) ${ }^{6,7}$ Bin Li, ${ }^{\prime}$ Qingquan Liu ${ }^{3}$

'The Department of Acupuncture and Moxibustion, Beijing Hospital of Traditional Chinese Medicine, Capital Medical University, Beijing Key Laboratory of Acupuncture Neuromodulation, Beijing 1000I0, People's Republic of China; ${ }^{2}$ Beijing University of Chinese Medicine, Beijing 100029, People's Republic of China; ${ }^{3}$ Beijing Hospital of Traditional Chinese Medicine, Capital Medical University, Beijing I000I0, People's Republic of China; ${ }^{4}$ Beijing Xiao Tang Shan Hospital, Beijing 102200, People's Republic of China; ${ }^{5}$ The First Clinical Medical School, Beijing University of Chinese Medicine, Beijing 100029, People's Republic of China; ${ }^{6}$ School of Biological Sciences, Nanyang Technological University, Singapore 63755I, Singapore; ${ }^{7}$ Department of Microbiology, Tumor and Cell Biology (MTC), Karolinska Institutet, Stockholm 17177, Sweden
\end{abstract}

*These authors contributed equally to this work

\section{Correspondence: Bin Li}

Beijing Hospital of Traditional Chinese

Medicine, Capital Medical University,

Beijing Key Laboratory of Acupuncture

Neuromodulation, No. 23 Gallery Street,

Beijing 100010, People's Republic of China

Email libin0314a@I26.com

Qingquan Liu

Beijing Hospital of Traditional Chinese

Medicine, Capital Medical University, No.

23 Gallery Street, Beijing I000 I0, People's

Republic of China

Email liuqingquan2003@I26.com
Purpose: To investigate the psychological impact of cases of coronavirus disease 19 (COVID-19) on medical staff of Beijing Xiaotangshan Hospital.

Methods: The 287 online questionnaires were distributed to medical staff working at Beijing Xiaotangshan Hospital, comprising three main sections and 17 questions: basic information, current departmental position, and the 12-item General Health Questionnaire (GHQ-12). The threshold for emotional distress was defined to be a total score of 4 on the GHQ-12 and above.

Results: A total of 255 members of medical staff participating in this study presented an emotional distress rate of $17 \%$. Members who were male, aged 50-59, married with children, positioned as doctors, and in administration were the population with the highest rate of emotional distress. Furthermore, the severity of emotional distress among those under 30 was significantly lower than those aged 30-39 and 50-59. Doctors and other occupations shared a lower level of satisfaction on routine activities compared with nurses, so did staff in the administration compared with those who were working in screening or logistic departments. Besides, males and staff of the confirmation department had more difficulty in concentrating than females and those of the screening department, respectively.

Conclusion: Medical staff working at Xiaotangshan Hospital underwent relatively low levels of emotional distress thanks to sufficient medical and psychological preparations. However, special attention should be paid to those who were male, married with children, senior, doctors, in administration, and in the confirmation department.

Keywords: COVID-19, psychological impact, medical staff, Beijing, GHQ-12

\section{Introduction}

Coronavirus disease-19 (COVID-19) is an emerging infectious viral disease caused by a Severe Acute Respiratory Syndrome (SARS)-like coronavirus, and the typical symptoms of COVID-19 are fever, cough, and fatigue. ${ }^{1}$ The first COVID-19 outbreak occurred in Wuhan, China, and has caused serious damage worldwide. ${ }^{2}$ As of May 30, 2020, more than 210 countries and regions have announced domestic cases of COVID-19, and there have been 5,934,936 confirmed cases globally, including 367,166 death cases. $^{3}$ Despite a large number of epidemiological studies on COVID-19 being reported, ${ }^{1,4,5}$ relatively little information was available regarding the psychological impact on medical staff on the frontline during the outbreak.

Medical staff are fighters on the frontline who were exposed to and at high risk of being infected by COVID-19, on top of having long working hours and enormous stress. The taxing workload made it extremely difficult for them to meet the health standards, and the combination of physical and mental exhaustion can lead to 
a more frequent occurrence of psychological problems. ${ }^{6}$ Previous studies on other infectious diseases (eg, SARS) have demonstrated that medical staff experienced severe emotional stress including burnout, traumatic experience, anxiety, depressive symptoms, and post-traumatic stress disorder during and after the outbreak..$^{7-10}$ During the outbreak of COVID-19, several studies aimed to detect the mental health of medical staff were also conducted, stating that the medical staff suffered varying degrees of insomnia, fear, stress, anxiety, depression, somatization, and obsessive-compulsive symptoms, indicating targeted strategies toward improving the mental health should be provided. ${ }^{11-15}$

Beijing, the capital of China, faced great challenges in preventing the resurgence of COVID-19 cases. On March 16, 2020, Beijing Xiaotangshan Hospital, employed for quarantine during the SARS outbreak previously, was renovated to be the designated hospital for the screening and treating of COVID-19 cases. Before the official reopening, Xiaotangshan Hospital had been entirely renovated with more than 1,000 beds and sufficient medical supplies. ${ }^{16}$ Meanwhile, Beijing authorities had arranged multiple training to enable all staff to scientifically understand COVID-19. Doctors from the respiratory department would introduce the latest guidelines of COVID-19, as well as the management of respiratory diseases to medical staff from other departments. Then all the staff were sent to an isolation ward in Beijing Ditan Hospital (a hospital for infectious diseases) to become familiar with the process of screening and treating patients with COVID-19. Additionally, peer support programs were set up to assist medical staff during the period of working at Xiaotangshan Hospital, in which both superiors and colleagues were organized to provide a supportive institutional response to address the feedback and needs from individuals, and acquaintances were distributed in the same medical group. Psychological counseling was also regularly provided by the psychologists before and during medical staff working at Xiaotangshan Hospital.

Researchers have pointed out that the lack of social support and preventive strategies is a risk factor for mental disorders during the COVID-19 crisis. $^{17}$ Thus, we assumed that medical staff working at Beijing Xiaotangshan Hospital may suffer minor psychological problems with the abovementioned preparations. This study aims to use the 12-item General Health Questionnaire (GHQ-12), which has been used to assess the psychological effect on medical staff of the SARS outbreak, ${ }^{18}$ to describe the mental impact of COVID-19 on medical staff who worked at Beijing Xiaotangshan Hospital.

\section{Methods}

\section{Participants}

We distributed 287 self-administered questionnaires from March 20 to March 29, 2020. The medical staff consisted of three categories of occupation: doctors, nurses, and others (pharmacists, medical imaging technologists, medical chemists, medical officers, cleaners, security guards, etc.), and four departments: the confirmation department (which treated confirmed cases), the screening department (which screened cases), administration, and the logistics department. We sent out questionnaires online to ensure the participation of all medical staff from different departments. Participation was strictly voluntary and anonymous. The purpose of this study was stated in the introduction on the first page of the questionnaires, and participants had to sign the online informed consent forms before they answered the questions. All the questions were compulsory to ensure a complete set of answers from every participant.

\section{Instrument}

The questionnaire contains three main sections and 17 questions: basic information (gender, age, and marital status), current departmental position (doctors, nurses, or others; confirmation department, screening department, logistical department, or administration) at Xiaotangshan Hospital and a common scale. There are multiple scales that have been used to assess the psychological health during the COVID-19 outbreak, such as the Impact of Events Scale, ${ }^{19}$ the Hospital Anxiety and Depression Scale ${ }^{20}$ and the General Health Questionnaire-28. ${ }^{21}$ Due to the intensive schedule of medical staff, we only chose the GHQ-12 which has been used in various studies for more than a decade. The GHQ-12 was designed by Goldberg $^{22}$ to detect non-specific psychiatric morbidity by utilizing a 12-item self-assessment, and each item is evaluated by four indexes. Additionally, several studies have demonstrated that its Chinese version has satisfactory reliability, good sensitivity, and high specificity for assessing mental disorders. ${ }^{23,24}$ Therefore, the GHQ-12 has been adopted widely. ${ }^{25,26}$ The scores for responses to positive statements were $0=$ better than usual or same as usual, and $1=$ less than usual or much less than usual. The 
scores for responses to negative statements were $0=$ not at all or no more than usual, and $1=$ rather more than usual or much more than usual. A total score was calculated after the completion of the entire set of questions, and the threshold was defined at 4 to identify emotional distress. ${ }^{27}$

\section{Statistical Analysis}

All analyses were performed using SPSS 22.0 (IBM Corporation, Armonk, NY, USA). Numbers and proportions were used to describe categorical variables which were evaluated using chi-square test, Fisher Exact test, or Kruskal-Wallis $H$-test. Mean and standard deviation (SD) were used to describe continuous variables, and differences across each variable among groups were assessed using Wilcoxon rank-sum test or Kruskal-Wallis $H$-test. Post-hoc comparison was conducted using Nemenyi Rank-Sum test. In order to detect the association between demographic characteristics and severity of emotional distress, we used whole demographic characteristics as independent variables and the total level of emotional distress (GHQ-12 score $\geq 4$ ) as dependent variables, and performed logistic regression analysis to predict the likelihood of emotional distress. Statistical significance was set at $P<0.05$ (two-tailed).

\section{Ethics Approval}

This study was reviewed and approved as exempt by the Medical Ethics Committee of Beijing Hospital of Traditional Chinese Medicine as a low risk with no patient intervention (Ethical Statement File). The objective and purpose of the study were verified briefly to the study participants, and the collected data were anonymous and treated as confidential. Also, online consent was received from all the study participants before conducting the survey. This study was conducted in accordance with the Declaration of Helsinki.

\section{Results}

Out of 287 medical staff of Xiaotangshan Hospital, 255 responded, rendering the response rate of $88.9 \% ; 16.7 \%$ of the respondents scored 4 and higher, indicating a relatively small proportion of the sample with emotional distress in participants.

The demographic characteristics of the participants are presented in Table 1. In a total of 255 respondents, the ratio of females to males was almost five to one. Also, more than half of the participants were under 40 years old. Marital status was divided into three categories: single, married with children, and married without children. The category of participants married with children was greater than the sum of the other two categories. Doctors and nurses accounted for $78.0 \%$ of the whole sample, $60.0 \%$ medical staff were in the screening department, of which nurses occupied $63.4 \%$. The distribution of doctors, nurses, and other staff in different departments showed a significant difference $(P<0.001$, Supplementary Table 1).

Table 1 also shows the number and percentage of participants with or without emotional distress. Among all five demographic variables, being male (23.3\%), aged 50-59 (23.1\%), married with children (19.9\%), doctors $(22.4 \%)$, and staff in administration $(25.0 \%)$ occupied the highest proportion of emotional distress in individual variables. No significant differences were found among the five characteristics regarding the proportion of whole sample with emotional distress. In terms of the severity of emotional distress (the total score of GHQ-12) in different characteristics, only the category of age presented a significant difference (Table 1). In particular, those aged under 30 years old suffered less emotional distress than those aged 30-39 $(P=0.027)$, and those aged 50-59 $(P=0.016$, Supplementary Table 2$)$.

Table 2 presents a significant difference on item 7 of GHQ-12 in occupation variables $(P=0.018)$, and significant differences were found in items $1(P=0.035)$ and 7 $(P=0.028)$ in department variables (Table 3$)$. Post-hoc comparisons (Supplementary Table 3) were conducted to examine the differences across occupation and department, finding significant differences in doctors versus nurses ( $P=0.013)$, nurses versus others $(P=0.025)$, the screening department versus the administration $(P=0.003)$ and the administration versus the logistics department $(P=0.049)$ on item 7, while the confirmation department versus the screening department $(P=0.009)$ showed a significant difference on item 1. Moreover, each GHQ-12 item was analyzed according to gender differences, and only item 1 had a significant difference $(P=0.018)$, indicating men are less resilient to stress-induced attention deficits (Supplementary Table 4). However, logistic regression analysis indicated that no probable factor was able to predict the mental health of the participants (Supplementary Table 5).

\section{Discussion}

Emotional distress, including symptoms of depression and anxiety, manifests as loss of social function and selfconfidence. $^{24,28}$ The response rate to our study on the mental impact of the COVID-19 outbreak on the medical 
Table I Demographic Characteristics of 255 Medical Staff Associated with Emotional Distress and GHQ-12 Total Score

\begin{tabular}{|c|c|c|c|c|c|c|}
\hline Variables & $\begin{array}{l}\text { Total, } \\
\text { n (\%) }\end{array}$ & $\begin{array}{l}\text { Emotional } \\
\text { Distress, n (\%) }\end{array}$ & $\begin{array}{l}\text { No Emotional } \\
\text { Distress, n (\%) }\end{array}$ & $P I$ & $\begin{array}{l}\text { GHQ-I } 2 \text { Total Score } \\
\text { Mean (SD) }\end{array}$ & P2 \\
\hline $\begin{array}{l}\text { Sex } \\
\qquad \text { Male } \\
\text { Female }\end{array}$ & $\begin{array}{l}43(16.9) \\
212(83.1)\end{array}$ & $\begin{array}{l}10(23.3) \\
33(15.6)\end{array}$ & $\begin{array}{l}33(76.7) \\
179(84.4)\end{array}$ & $0.219^{a}$ & $\begin{array}{l}1.98(2.14) \\
1.65(2.20)\end{array}$ & $0.210^{\mathrm{b}}$ \\
\hline $\begin{array}{l}\text { Age, years } \\
\quad<30 \\
30-39 \\
40-49 \\
50-59\end{array}$ & $\begin{array}{l}78(30.6) \\
122(47.8) \\
42(16.5) \\
13(5.1)\end{array}$ & $\begin{array}{l}10(12.8) \\
24(19.7) \\
6(14.3) \\
3(23.1)\end{array}$ & $\begin{array}{l}68(87.2) \\
98(80.3) \\
36(85.7) \\
10(76.9)\end{array}$ & $0.54 I^{c}$ & $\begin{array}{l}1.21(1.65) \\
1.94(2.39) \\
1.64(2.26) \\
2.62(2.50)\end{array}$ & $0.035^{d}$ \\
\hline $\begin{array}{l}\text { Marital status } \\
\text { Single } \\
\text { Married with children } \\
\text { Married without children }\end{array}$ & $\begin{array}{l}83(32.5) \\
146(57.3) \\
26(10.2)\end{array}$ & $\begin{array}{l}10(12.0) \\
29(19.9) \\
4(15.4)\end{array}$ & $\begin{array}{l}73(88.0) \\
117(80.1) \\
22(84.6)\end{array}$ & $0.309^{\mathrm{a}}$ & $\begin{array}{l}1.17(1.47) \\
2.04(2.47) \\
1.50(2.18)\end{array}$ & $0.059^{d}$ \\
\hline $\begin{array}{l}\text { Occupation } \\
\text { Doctor } \\
\text { Nurse } \\
\text { Others }\end{array}$ & $\begin{array}{l}76(29.8) \\
123(48.2) \\
56(22.0)\end{array}$ & $\begin{array}{l}17(22.4) \\
17(13.8) \\
9(16.1)\end{array}$ & $\begin{array}{l}59(77.6) \\
106(86.2) \\
47(83.9)\end{array}$ & $0.289^{a}$ & $\begin{array}{l}2.07(2.47) \\
\mathrm{I} .50(2.06) \\
\mathrm{I} .66(2.05)\end{array}$ & $0.28 \mathrm{I}^{\mathrm{d}}$ \\
\hline $\begin{array}{l}\text { Current work department } \\
\text { Confirmation department } \\
\text { Screening department } \\
\text { Administration } \\
\text { Logistics department }\end{array}$ & $\begin{array}{l}52(20.4) \\
153(60.0) \\
20(7.8) \\
30(11.8)\end{array}$ & $\begin{array}{l}\text { II }(21.2) \\
23(15.0) \\
5(25.0) \\
4(13.3)\end{array}$ & $\begin{array}{l}41(78.8) \\
130(85.0) \\
15(75.0) \\
26(86.7)\end{array}$ & $0.520^{\mathrm{a}}$ & $\begin{array}{l}2.02(2.76) \\
1.56(1.98) \\
2.20(2.07) \\
1.53(2.21)\end{array}$ & $0.377^{d}$ \\
\hline
\end{tabular}

Notes: ${ }^{a}$ Categorical data were detected by chi-square test; ${ }^{\mathrm{b}}$ Continuous data were analyzed using Wilcoxon rank-sum test; ${ }^{\mathrm{c} C a t e g o r i c a l}$ data were detected by KruskalWallis $\mathrm{H}$-test; ${ }^{\mathrm{d}}$ Continuous data were analyzed using Kruskal-Wallis $\mathrm{H}$-test.

Abbreviations: GHQ-12, 12-item General Health Questionnaire; SD, standard deviation.

Table 2 Association Between GHQ-I2 Items and Occupation

\begin{tabular}{|c|c|c|c|c|}
\hline GHQ-I 2 Items & Doctors, n (\%) & Nurses, n (\%) & Others, n (\%) & $\boldsymbol{P}$ \\
\hline I. Able to concentrate & $67(88.2)$ & II 8 (95.9) & $52(92.9)$ & 0.115 \\
\hline 2. Too worry to sleep & $27(35.5)$ & $45(36.6)$ & $20(35.7)$ & 0.987 \\
\hline 3. Playing a useful part & $73(96.1)$ & I2I (98.4) & $55(98.2)$ & 0.569 \\
\hline 4. Capable of making decisions & $66(86.6)$ & $116(94.3)$ & $54(96.4)$ & 0.068 \\
\hline 5. Under stress & $19(25.0)$ & $28(22.8)$ & II (19.6) & 0.768 \\
\hline 6. Could not overcome difficulties & II (I4.5) & $8(6.5)$ & $5(8.9)$ & 0.172 \\
\hline 7. Enjoy your routine activities & $42(55.3)$ & $89(72.4)$ & $31(55.4)$ & 0.018 \\
\hline 8. Face up to problems & $73(96.1)$ & II 8 (95.9) & $54(96.4)$ & 1.000 \\
\hline 9. Feeling unhappy and depressed & $20(26.3)$ & $22(17.9)$ & $10(17.9)$ & 0.310 \\
\hline 10. Losing confidence & $5(6.6)$ & $7(5.7)$ & $4(7.1)$ & 0.893 \\
\hline II. Thinking of self as worthless & $4(5.3)$ & $7(5.7)$ & I (I.8) & 0.593 \\
\hline 12. Feeling reasonably happy & 64 (84.2) & $109(88.6)$ & 48 (85.7) & 0.655 \\
\hline
\end{tabular}

Note: Data were examined using chi-square test and Fisher Exact test.

Abbreviation: GHQ-12, 12-item General Health Questionnaire.

staff working at Xiaotangshan Hospital was relatively high, which was $89 \%$. In our finding, $16.7 \%$ of the medical staff experienced emotional distress. Male, aged 50-59, people married with children, doctors, and staff in administration occupied the highest proportion of the population with emotional distress in each demographic variable. Staff aged under 30 years old suffered less than those aged 30-39, and those aged 50-59 in terms of the severity of emotional distress. Additionally, doctors and other occupations were unable to enjoy routine activities as 
Table 3 Association Between GHQ-I2 Items and Department

\begin{tabular}{|c|c|c|c|c|c|}
\hline GHQ-I 2 Items & $\begin{array}{l}\text { Confirmation } \\
\text { Department, n (\%) }\end{array}$ & $\begin{array}{l}\text { Screening } \\
\text { Department, n (\%) }\end{array}$ & $\begin{array}{l}\text { Administration, } \\
\text { n (\%) }\end{array}$ & $\begin{array}{l}\text { Logistics } \\
\text { Department, n (\%) }\end{array}$ & $P$ \\
\hline I. Able to concentrate & $44(84.6)$ & $147(96.1)$ & $18(90.0)$ & $28(93.3)$ & 0.035 \\
\hline 2. Too worried to sleep & $19(36.5)$ & $59(38.6)$ & $5(25.0)$ & $9(30.0)$ & 0.581 \\
\hline 3. Playing a useful part & $50(96.2)$ & $149(97.4)$ & $20(100.0)$ & $30(100.0)$ & 0.810 \\
\hline 4. Capable of making decisions & $47(90.4)$ & $143(93.5)$ & $18(90)$ & $28(93.3)$ & 0.784 \\
\hline 5. Under stress & II (2I.2) & $35(22.9)$ & $6(30.0)$ & $6(20.0)$ & 0.848 \\
\hline 6. Could not overcome difficulties & $6(11.5)$ & $12(7.8)$ & $2(10.0)$ & $4(13.3)$ & 0.632 \\
\hline 7. Enjoy your routine activities & $31(59.6)$ & $105(68.6)$ & $7(35.0)$ & $19(63.3)$ & 0.028 \\
\hline 8. Face up to problems & $47(90.4)$ & $150(98.0)$ & $20(100.0)$ & $28(93.3)$ & 0.054 \\
\hline 9. Feeling unhappy and depressed & $10(19.2)$ & $30(19.6)$ & $7(35.0)$ & $5(16.7)$ & 0.394 \\
\hline 10. Losing confidence & $5(9.6)$ & $8(5.2)$ & $3(15.0)$ & $0(0.0)$ & 0.092 \\
\hline II. Thinking of self as worthless & $44(84.6)$ & $147(96.1)$ & $18(90.0)$ & $28(93.3)$ & 0.035 \\
\hline 12. Feeling reasonably happy & $19(36.5)$ & $59(38.6)$ & $5(25.0)$ & $9(30.0)$ & 0.581 \\
\hline
\end{tabular}

Note: Data were examined using chi-square test and Fisher Exact test. Abbreviation: GHQ-12, 12-item General Health Questionnaire.

compared to nurses, so did those in the administration compared with those in the screening department or the logistics department, which might be associated with higher proportion of nurses in screening department. Also, medical staff in the confirmation department felt it harder to concentrate than those in the screening department. Similarly, male participants showed more difficulties in attention than female participants under pressure.

The low rate of emotional distress in our study is inconsistent with previous findings from studies on the 2003 SARS outbreak. ${ }^{18,29}$ Nickell et al ${ }^{18}$ used GHQ-12 to investigate the psychosocial effects on hospital staff in Toronto during the SARS outbreak, demonstrating that the disease had strong negative effects on two-thirds of hospital staff, and $29 \%$ of the participants showed emotional distress. Moreover, Chan and $\mathrm{Huak}^{29}$ found that the prevalence of psychiatric disorders in Singapore is $35 \%$ of doctors and $25 \%$ of nurses using the GHQ-28 questionnaire. Besides, several studies conducted in China during the COVID-19 outbreak (late February to early March of 2020) show a high rate of psychological problems within medical staff. ${ }^{13,30}$ Zhang et $\mathrm{al}^{30}$ found that medical health workers $(n=927)$ in Wuhan had a prevalence of insomnia $(38.4 \%)$, anxiety (13.0\%), depression (12.2\%), somatization (1.6\%), and obsessive-compulsive symptoms (5.3\%). Furthermore, $\mathrm{Lu}$ et $\mathrm{al}^{13}$ revealed that $70.6 \%$ of medical staff $(\mathrm{n}=2,042)$ in Fuzhou suffered from moderate and severe fear, and 22.6\% of them unfolded mild-to-moderate anxiety, and staff working in the department of respiratory, emergency, infectious disease, and intensive care unit were more likely to feel fear, anxious, and depressed.
Compared with the abovementioned studies, the medical staff participating in our study manifested a more positive state of mind, which may be associated with the relatively stable situation and advanced coping strategies towards COVID-19 in Beijing. According to Chinese authorities, the confirmed cases in China had been decreasing since February 13, 2020. ${ }^{31}$ Since the COVID19 outbreak, Chinese medical staff were getting more familiar with the disease, rendering them more confident in facing the challenges. Furthermore, sufficient medical equipment and supplies, professional training, and solid peer support programs made them more deliberate and comfortable in treating and conducting isolation on the cases.

However, there are certain potential limitations to our study. First, considering the hectic schedule of the medical staff, the study was conducted in merely a few days as a single survey to capture their mental health, so it failed to obtain the data on the psychological changes during the entire working period. Second, the questionnaire was relatively simplified, lacking a comprehensive understanding of other potential variables, including pre-existing mental problems (eg, major depression ${ }^{32}$ ) and personal issues (eg, maltreatment during childhood ${ }^{33}$ or temperament ${ }^{34}$ ) before the outbreak, and that the qualitative methods, such as interviews, could not be simultaneously performed. Another limitation is that the emotional assessment was based on an online survey and a self-report tool, which are lacking in the professional diagnosis of psychiatrists. Besides, staff in our study had regular training and received mental counseling, they prepared well in advance, thus the relative lower 
rate of emotional distress in our study may not be generalized. Despite those limitations, our study was the first to describe the psychological condition of the medical staff at Xiaotangshan Hospital with a high response rate during the outbreak of COVID-19, suggesting that sufficient medical supplies, professional training, and supportive programs may be associated with better mental health of medical staff. Meanwhile, more attention should be paid to medical staff who were male, married with children, seniors, doctors, in the administration and conformation department, and targeted psychological counseling should be implemented among doctors and those who were in the administration and confirmation department during the COVID-19 outbreak. We intend to provide our findings as valuable data to other regions where the rough battle against COVID-19 is still ongoing.

\section{Conclusion}

The pandemic of COVID-19 caused emotional distress on $16.7 \%$ of the medical staff working at Xiaotangshan Hospital. The distress rate was numerically higher in males, people married with children, the seniors, doctors, and staff in administration. Routine activities were more unavailable to doctors and other occupations than nurses, which was also the reality for administrative staff in comparison to staff in screening or logistics department. Also, the concentration issue was more severe for medical staff in the confirmation department than those in the screening department. These findings highlight the importance of medical and psychological preparations including sufficient medical supplies, respiratory diseases and COVID19 guideline learning, peer support programs, and regular psychological counseling for medical staff on the frontline fighting against COVID-19.

\section{Acknowledgments}

We would like to thank all the medical staff who have fought on the frontline against COVID-19.

\section{Author Contributions}

All authors made substantial contributions to the conception and design, acquisition of data, or analysis and interpretation of data; took part in drafting the article or revising it critically for important intellectual content; agreed to submit to the current journal; gave final approval of the version to be published; and agree to be accountable for all aspects of the work.

\section{Funding}

This work was supported by National Science and Technology Emergency Program (Grant No. 2020YFC0841600), National Natural Science Foundation of China (Grant No.62041701) and Beijing Municipal Administration of Hospitals' Youth Program (Grant No. QML 20150904).

\section{Disclosure}

The authors report no conflicts of interest in this work.

\section{References}

1. Huang C, Wang Y, Li X, et al. Clinical features of patients infected with 2019 novel coronavirus in Wuhan, China. Lancet (London, England). 2020;395(10223):497-506. doi:10.1016/S0140-6736(20) 30183-5

2. Wu JT, Leung K, Leung GM. Nowcasting and forecasting the potential domestic and international spread of the 2019-nCoV outbreak originating in Wuhan, China: a modelling study. Lancet (London, England). 2020;395(10225):689-697. doi:10.1016/S0140-6736(20) 30260-9

3. Organization WH. Coronavirus disease 2019 (COVID-19) situation report - 101; 2020. Available from: https://www.who.int/docs/defaultsource/coronaviruse/situation-reports/20200531-covid-19-sitrep-132. pdf?sfvrsn=d9c2eaef_2. Accessed December 12, 2020.

4. Zhu N, Zhang D, Wang W, et al. A novel coronavirus from patients with pneumonia in China, 2019. $N$ Engl J Med. 2020;382 (8):727-733. doi:10.1056/NEJMoa2001017

5. Chan JF, Yuan S, Kok KH, et al. A familial cluster of pneumonia associated with the 2019 novel coronavirus indicating person-toperson transmission: a study of a family cluster. Lancet (London, England). 2020;395(10223):514-523. doi:10.1016/S0140-6736(20) 30154-9

6. Shalev D, Shapiro PA. Epidemic psychiatry: the opportunities and challenges of COVID-19. Gen Hosp Psychiatry. 2020;64:68-71. doi:10.1016/j.genhosppsych.2020.03.009

7. Maunder RG, Lancee WJ, Rourke S, et al. Factors associated with the psychological impact of severe acute respiratory syndrome on nurses and other hospital workers in Toronto. Psychosom Med. 2004;66 (6):938-942. doi:10.1097/01.psy.0000145673.84698.18

8. Tam CW, Pang EP, Lam LC, Chiu HF. Severe acute respiratory syndrome (SARS) in Hong Kong in 2003: stress and psychological impact among frontline healthcare workers. Psychol Med. 2004;34 (7):1197-1204. doi:10.1017/S0033291704002247

9. Lancee WJ, Maunder RG, Goldbloom DS. Prevalence of psychiatric disorders among Toronto hospital workers one to two years after the SARS outbreak. Psychiatr Serv. 2008;59(1):91-95. doi:10.1176/ ps.2008.59.1.91

10. Hong X, Currier GW, Zhao X, Jiang Y, Zhou W, Wei J. Posttraumatic stress disorder in convalescent severe acute respiratory syndrome patients: a 4-year follow-up study. Gen Hosp Psychiatry. 2009;31 (6):546-554. doi:10.1016/j.genhosppsych.2009.06.008

11. Xiao H, Zhang Y, Kong D, Li S, Yang N. The effects of social support on sleep quality of medical staff treating patients with coronavirus disease 2019 (COVID-19) in January and February 2020 in China. Med Sci Monit. 2020;26:e923549. doi:10.12659/MSM.923921

12. Cao J, Wei J, Zhu H, et al. A study of basic needs and psychological wellbeing of medical workers in the fever clinic of a Tertiary General Hospital in Beijing during the COVID-19 outbreak. Psychother Psychosom. 2020;89(4):252-254. doi:10.1159/000507453 
13. Lu W, Wang H, Lin Y, Li L. Psychological status of medical workforce during the COVID-19 pandemic: a cross-sectional study. Psychiatry Res. 2020;288:112936. doi:10.1016/j.psychres.2020.112936

14. Bohlken J, Schömig F, Lemke MR, Pumberger M, Riedel-Heller SG. [COVID-19 pandemic: stress experience of healthcare workers a short current review]. Psychiatr Prax. 2020;47(4):190-197. German.

15. Tan BYQ, Chew NWS, Lee GKH, et al. Psychological impact of the COVID-19 pandemic on health care workers in Singapore. Ann Intern Med. 2020;173(4):317-320. doi:10.7326/M20-1083

16. Paper T. 17 years later, Beijing Xiaotangshan Hospital was reopened to defend imported epidemic; 2020. Available from: https://www.thepaper. cn/newsDetail_forward_6552177. Accessed December 12, 2020.

17. Serafini G, Parmigiani B, Amerio A, Aguglia A, Sher L, Amore M. The psychological impact of COVID-19 on the mental health in the general population. QJM. 2020;113(8):531-537. doi:10.1093/qjmed/hcaa201

18. Nickell LA, Crighton EJ, Tracy CS, et al. Psychosocial effects of SARS on hospital staff: survey of a large tertiary care institution. CMAJ. 2004;170(5):793-798. doi:10.1503/cmaj.1031077

19. Horowitz M, Wilner N, Alvarez W. Impact of event scale: a measure of subjective stress. Psychosom Med. 1979;41(3):209-218. doi:10.1097/00006842-197905000-00004

20. Zigmond AS, Snaith RP. The hospital anxiety and depression scale. Acta Psychiatr Scand. 1983;67(6):361-370. doi:10.1111/j.16000447.1983.tb09716.x

21. Goldberg D. Manual of the General Health Questionnaire. Windsor: NFER: Nelson Publishing Co; 1978.

22. Goldberg D. The detection of psychiatric illness by questionnaire. Maudsley Monograph. 1973;21:1.

23. Guan M, Han B. Factor structures of general health questionnaire-12 within the number of kins among the rural residents in China. Front Psychol. 2019;10:1774. doi:10.3389/fpsyg.2019.01774

24. Liang Y, Wang L, Yin X. The factor structure of the 12-item general health questionnaire (GHQ-12) in young Chinese civil servants. Health Qual Life Outcomes. 2016;14(1):136. doi:10.1186/s12955-016-0539-y

25. Romppel M, Braehler E, Roth M, Glaesmer H. What is the General Health Questionnaire-12 assessing? Dimensionality and psychometric properties of the General Health Questionnaire-12 in a large scale German population sample. Compr Psychiatry. 2013;54 (4):406-413. doi:10.1016/j.comppsych.2012.10.010
26. Abubakar A, Fischer R. The factor structure of the 12-item General Health Questionnaire in a literate Kenyan population. Stress Health. 2012;28(3):248-254. doi:10.1002/smi.1420

27. Goldberg D. General Health Questionnaire (GHQ-12). Windsor, UK: NFER-Nelson; 1992.

28. Ropaj E, Jones A, Dickson JM, Gill Z, Taylor PJ. Are negative beliefs about psychosis associated with emotional distress in adults and young people with such experiences? A meta-analysis. Psychol Psychother. 2020. doi:10.1111/papt.12271

29. Chan AO, Huak CY. Psychological impact of the 2003 severe acute respiratory syndrome outbreak on health care workers in a medium size regional general hospital in Singapore. Occup Med. 2004;54 (3):190-196. doi:10.1093/occmed/kqh027

30. Zhang WR, Wang K, Yin L, et al. Mental health and psychosocial problems of medical health workers during the COVID-19 epidemic in China. Psychother Psychosom. 2020:1-9.

31. China NHCotPsRo. Press conference of COVID-19; 2020. Available from: http://www.nhc.gov.cn/xcs/fkdt/202002/ 2db5729cfb674b37b48820a098c8bf88.shtml.Accessed December 12, 2020.

32. Di Nicola M, Dattoli L, Moccia L, et al. Serum 25-hydroxyvitamin $\mathrm{D}$ levels and psychological distress symptoms in patients with affective disorders during the COVID-19 pandemic. Psychoneuroendocrinology. 2020;122:104869. doi:10.1016/j.psyneuen.2020.104869

33. Pompili M, Innamorati M, Lamis DA, et al. The associations among childhood maltreatment, "male depression" and suicide risk in psychiatric patients. Psychiatry Res. 2014;220(1-2):571-578. doi:10.1016/j. psychres.2014.07.056

34. Moccia L, Janiri D, Pepe M, et al. Affective temperament, attachment style, and the psychological impact of the COVID-19 outbreak: an early report on the Italian general population. Brain Behav Immun. 2020;87:75-79. doi:10.1016/j.bbi.2020.04.048
Psychology Research and Behavior Management

\section{Publish your work in this journal}

Psychology Research and Behavior Management is an international, peer-reviewed, open access journal focusing on the science of psychology and its application in behavior management to develop improved outcomes in the clinical, educational, sports and business arenas. Specific topics covered in the journal include: Neuroscience, memory and decision making; Behavior modification and management; Clinica applications; Business and sports performance management; Social and developmental studies; Animal studies. The manuscript management system is completely online and includes a very quick and fair peer-review system, which is all easy to use. Visit http://www dovepress.com/testimonials.php to read real quotes from published authors. 